\title{
PHENOLICS AND ENZYMES OF PHENOL METABOLISM IN 'SEEDLESS' AND 'CALCUTTIA' CULTIVARS OF LITCHI GROWN IN NORTH INDIA
}

\author{
C. KAUR ${ }^{\mathrm{a}}$, S. Sharma ${ }^{\mathrm{a} *}$ and S. NAVPREM ${ }^{\mathrm{b}}$

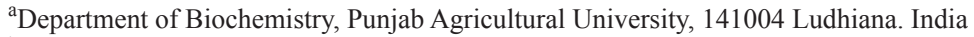 \\ ${ }^{b}$ Department of Fruit Science, Punjab Agricultural University, 141004 Ludhiana. India
}

(Received: 2 February 2018; accepted: 23 March 2018)

\begin{abstract}
Present investigation reports the variability in phenolics and activities of some enzymes involved in their metabolism in pericarp tissue of 'Calcuttia' and 'Seedless' cultivars harvested at one week interval after fruit set. Total phenolics, flavonols, and phenolic acid contents in litchi fruit pericarp increased after 49 days following fruit set (DAFS), while proanthocyanins showed a small increment initially and then decreased significantly up to maturity. Polyphenol oxidase, phenylalanine ammonia lyase, and cinnamate-4-hydroxylase activities followed the similar trend as observed in phenolic content at respective developmental stages, while peroxidase activity in pericarp was low at initial stages and increased gradually with fruit development. Higher phenolic content with low polyphenol oxidase activity in pericarp during initial stages of fruit development in 'Seedless' as compared to 'Calcuttia' cultivar suggests the slow ripening. A negative correlation between anthocyanin content and anthocyanase activity was recorded. Total phenolic constituents, ferric reducing antioxidant power (FRAP), and 2,2-diphenyl-1-picryl-hydrazyl (DPPH) radical scavenging activity showed positive correlation with higher values of these parameters in 'Seedless' as compared to 'Calcuttia' cultivar. Knowing the phenolic profiles, antioxidant activity, and activity of related enzymes during fruit development gives the insights into its potential application to reduce the post-harvest browning of litchi.
\end{abstract}

Keywords: pericarp, litchi, phenolics, anthocyanins, enzymes, antioxidant activity

Litchi (Litchi chinensis Sonn.) is a non-climacteric subtropical fruit that belongs to the family Sapindaceae. It is a rich source of different classes of compounds such as phenolics, anthocyanins, lignans, terpenes, and fatty acids, etc. (WANG et al., 2011). The colour of litchi fruit pericarp (LFP) is provided by a number of pigments, including chlorophyll, carotenoids, anthocyanins, and phenolic compounds, and changes from green to yellow to red during fruit development. Variability in phenolic contents and antioxidant activities among different litchi species and cultivars from the same species has been reported by a number of authors (WANG et al., 2011; LiN et al., 2015). Litchi fruit rapidly loses its redness and browning of pericarp takes place once the fruit is harvested. Pericarp browning results in a short shelf life, affects the appearance of the fruit, reduces the commercial value, thus causes significant economic losses to growers as well as traders. Large quantity of pericarp and stone are produced during the processing of litchi for wine or juice purposes and are discarded as a waste product (Li et al., 2012). Pericarp is approximately $15 \%$ by weight of the whole fresh fruit, and contains large amounts of phenolic compounds including tannins, procyanidins, and anthocyanidins (ZHANG et al., 2000). These phenolics exhibit different health promoting and antioxidant activities (UPADHYAYA \& UPADHYAYA, 2017), and LFP has been considered a new source of phenolics in pharmaceuticals and food industry.

\footnotetext{
* To whom correspondence should be addressed.

Phone: +91-161-240960, ext 322; e-mail: suchetasharma_pau@pau.edu
} 
Fruit ripening in litchi is related to the elevated levels of phenylpropanoid derivatives (Sun et al., 2009). Phenylalanine ammonia lyase (PAL), cinnmate-4-hydroxylase (C4H), and 4-coumarate coenzyme A ligase are the core enzymes of phenylpropanoid pathway detected in LFP and increased PAL and C4H activities indicate accumulation of anthocyanins and phenolic constituents during fruit development (WANG et al., 2011). Phenylalanine ammonia lyase catalyses the conversion of phenylalanine to trans-cinnamic acid, which then acts as substrate for $\mathrm{C} 4 \mathrm{H}$ and gets converted to $p$-coumaric acid (SINGH et al., 2009). Peroxidase (POD) and polyphenol oxidase (PPO) enzymes play important roles in the oxidation of phenolic compounds in the litchi fruit. The post-harvest browning of LFP is due to the oxidation of phenolic compounds by PPO leading to the formation of brown coloured byproducts (JIANG et al., 2004) and degradation of anthocyanins by POD and PPO. Peroxidase indirectly degrades anthocyanins by following the anthocyanase-anthocyanidin-phenolics$\mathrm{H}_{2} \mathrm{O}_{2}$ reaction pathway, whereas anthocyanidin can act as a direct substrate for POD (ZHANG et al., 2005). Phenolics are present in the vacuoles, whereas enzyme of phenol metabolism exists in soluble or membrane bound forms in cytoplasm, mitochondria, and plastids. A gradual loss of membrane compartmentalization of pericarp tissues of litchi fruit after harvest results in contact of PPO and its substrate and causes enzyme catalysed oxidation to form the brown-coloured by-products (JIANG et al., 2004). Enzymatic browning of litchi fruit after harvest is major limitation for its storage, shelf life, quality, and commercial value. Thus, accumulation of phenolic compounds and the activities of enzymes involved in their metabolism play important role in fruit maturation and postharvest browning of LFP.

The present study was planned to investigate the levels of phenolic constituents and activities of enzymes of phenylpropanoid pathway in pericarp during fruit growth and development and antioxidant activity of litchi waste for their further use in food and pharmaceutical industries.

\section{Materials and methods}

\subsection{Plant materials}

Fruit of litchi cvs 'Calcuttia' and 'Seedless' were collected at different development stages from an orchard established at MS Randhawa, Fruit Research Station, Gangian (Dasuya), Hoshiarpur district of Punjab in Northern India after weekly interval from $22^{\text {nd }}$ April, 2016 (fruit set) up to final fruit harvest $\left(18^{\text {th }}\right.$ June). Uniform fruit of these cultivars from nearly 30 to 40 years old trees at different harvest stages were brought to the laboratory under cold conditions. Fruit were peeled, and pericarp was used for the estimation of phenolic constituents and different enzymatic activities.

\subsection{Measurements of phenolic constituents and antioxidant activity}

Pericarp tissues from fruit collected at different development stages were extracted with $80 \%$ hot methanol for $1 \mathrm{~h}$, and extracts were used for determination of total phenolic constituents (Swain \& Hillis, 1959), flavonols (BAlababa et al., 1974), and phenolic acids (WANG et al. 2011). Proanthocyanidins and anthocyanins were estimated according to the methods of Li and co-workers (2012) and RANGANNA (1997), respectively. Antioxidant activity of LFP was assessed by DPPH radical scavenging activity (Li et al., 2012) and FRAP assay (BENZIE \& STRAIN, 1999). 


\subsection{Enzymatic assays}

Litchi fruit pericarp $(0.1 \mathrm{~g})$ was homogenized with $0.05 \mathrm{M}$ phosphate buffer $(\mathrm{pH} 7.5)$ containing $1 \%$ polyvinylpyrrolidone (PVP). Homogenate was centrifuged at $4{ }^{\circ} \mathrm{C}$ for 15 min at $10000 \mathrm{~g}$ and supernatant thus obtained was used for assay of POD (SHANNON et al., 1966) and PPO (ZAUBERMAn et al., 1991). For POD (EC 1.11.1.7) activity, reaction mixture containing $0.1 \mathrm{ml}$ of extract, $3.5 \mathrm{ml}$ of sodium phosphate buffer $(0.5 \mathrm{M}, \mathrm{pH} 6.5)$, and $0.1 \mathrm{ml}$ of ortho-dianisidine solution was brought to $30^{\circ} \mathrm{C}$. The reaction was started by adding $0.1 \mathrm{ml}$ of $\mathrm{H}_{2} \mathrm{O}_{2}$ and the activity was recorded at $430 \mathrm{~nm}$ at $30 \mathrm{sec}$ intervals for $3 \mathrm{~min}$. POD activity was expressed as $\Delta \mathrm{OD} / \mathrm{min} / \mathrm{g}$ fresh weight. Polyphenol oxidase (EC 1.14.18.1) activity was determined in a reaction mixture containing $0.5 \mathrm{ml}$ of enzyme extract and $1 \mathrm{ml}$ phosphate buffer (0.05 M, pH 6.5) mixed with $0.5 \mathrm{ml}$ of $0.1 \mathrm{M}$ catechol. Enzyme activity was recorded at $410 \mathrm{~nm}$ for $3 \mathrm{~min}$ and expressed as $\Delta \mathrm{OD} / \mathrm{min} / \mathrm{g}$ fresh weight.

For PAL (EC 4.3.1.5) activity, LFP (0.1 g) was extracted with $2 \mathrm{ml}$ of sodium borate buffer $(0.05 \mathrm{M}, \mathrm{pH} 8.8)$ containing $0.1 \% \mathrm{PVP}$ and $5 \mathrm{mM}$ mercaptoethanol. Centrifugation was done at $12000 \mathrm{~g}$ at $4{ }^{\circ} \mathrm{C}$ for $15 \mathrm{~min}$ and the supernatant was used as enzyme source (Lister et al., 1996). Reaction mixture containing $100 \mu \mathrm{l}$ of enzyme extract, $1.9 \mathrm{ml}$ of $0.05 \mathrm{M}$ borate buffer ( $\mathrm{pH} \mathrm{8.8)}$, and $1 \mathrm{ml}$ of $20 \mathrm{mM}$ phenylalanine was incubated at $37{ }^{\circ} \mathrm{C}$ for $1 \mathrm{~h}$. Reaction was terminated by adding $0.2 \mathrm{ml}$ of $6 \mathrm{M}$ trichloroacetic acid, and absorbance of test samples was read at $290 \mathrm{~nm}$ against the control prepared by replacing the enzymatic extract with $0.1 \mathrm{ml}$ of buffer. Enzyme activity was calculated from the standard curve of cinnamic acid (5-35 $\mu \mathrm{g})$ and expressed as $\mu \mathrm{g}$ trans-cinnamic acid formed $/ \mathrm{min} / \mathrm{g}$ fresh weight.

For C4H (EC 1.14.13.11) assay (SINGH et al., 2009), LFP (0.1 g) was homogenized in 2 $\mathrm{ml}$ of $0.05 \mathrm{M}$ phosphate buffer ( $\mathrm{pH} 7.6$ ) containing $1 \mathrm{mM}$ mercaptoethanol. The homogenate was centrifuged at $5000 \mathrm{~g}$ for $10 \mathrm{~min}$, and the supernatant thus obtained was used for assaying C4H. To $0.2 \mathrm{ml}$ enzyme extract, $4.8 \mathrm{ml}$ of phosphate buffer, $2 \mathrm{mM}$ trans-cinnamic acid, and $0.05 \mathrm{mM}$ NADPH were added. The tubes were incubated at $30^{\circ} \mathrm{C}$ for $30 \mathrm{~min}$. Reaction was terminated by adding $1 \mathrm{ml}$ of $6 \mathrm{~N} \mathrm{HCl}$, and the $\mathrm{pH}$ was adjusted to 11 with $6 \mathrm{~N} \mathrm{NaOH}$. The absorbance of test samples was recorded at $310 \mathrm{~nm}$ in UV-Visible spectrophotometer. A standard curve of trans-cinnamic acid (20-100 $\mu \mathrm{g})$ was prepared, and enzyme activity was expressed as $\mu \mathrm{g}$ trans-cinnamic acid degraded $/ \mathrm{min} / \mathrm{g}$ fresh weight.

Anthocyanase (EC 2.4.1.295) activity was assayed by the method of DuCAMP-CoLLIN and co-workers (2007). Pericarp $(0.2 \mathrm{~g})$ was homogenized in $4 \mathrm{ml}$ of sodium acetate buffer $(0.1 \mathrm{M}, \mathrm{pH} 4)$ containing $0.1 \%$ PVP. Centrifuged the homogenate at $15000 \mathrm{~g}$ for $20 \mathrm{~min}$ at $4{ }^{\circ} \mathrm{C}$, and the supernatant was used for anthocyanase assay. To $1 \mathrm{ml}$ of enzyme extract, $4 \mathrm{ml}$ of $0.05 \mathrm{mM}$ cyanidin-3-glycoside (C-3G) solution was added and the mixture was incubated at $40{ }^{\circ} \mathrm{C}$ for $10 \mathrm{~min}$, followed by addition of $5 \mathrm{ml}$ of $0.1 \mathrm{M} \mathrm{HCl}$. The absorbance was read at $510 \mathrm{~nm}$ using sodium acetate buffer as blank. A standard curve $(0.5-2.5 \mu \mathrm{g})$ of C-3G was prepared, and enzyme activity was defined as $\mu \mathrm{g} \mathrm{C}-3 \mathrm{G}$ degraded $/ \mathrm{min} / \mathrm{g}$ fresh weight at $40{ }^{\circ} \mathrm{C}$.

\subsection{Statistical analysis}

The experiments were carried out in triplicates. Means, standard deviation, and critical differences in biochemical attributes of litchi at various developmental stages were determined using factorial $\mathrm{CRD}(\mathrm{P}<0.05$, ANOVA) with computer application CPCS-1. 


\section{Results and discussion}

\subsection{Phenolic constituents of litchi fruit pericarp}

Total phenolic contents (TPC) did not show significant variations at initial stages of fruit development; decreased rapidly from 35 to 42 days after fruit set (DAFS), and then increased significantly up to maturity at $5 \%$ significance level (Fig. 1). 'Seedless' litchi cultivar exhibited significantly higher TPC as compared to 'Calcuttia' during later stages of fruit harvest (49-56 DAFS). Initially, total flavonols increased significantly from 14 to 21 DAFS in 'Calcuttia', but during later stages of fruit development 'Seedless' exhibited significantly higher contents of flavonols and phenolic acids than 'Calcuttia' cultivar. Proanthocyanidins content in LFP was higher at initial stages, but decreased significantly from 21 to 42 DAFS in 'Calcuttia' and 14 to 42 DAFS in 'Seedless', and then at maturity, a slow increment was observed in both the cultivars. Proanthocyanidin content was higher in 'Seedless' litchi cultivar than 'Calcuttia' at all developmental stages with higher (1.5-2-fold) mean content. Phenolic acids decreased significantly up to middle stages of fruit development in both cultivars, and then a rapid increase was observed up to maturity ( $\mathrm{P}<0.05)$ (Fig. 2). Phenolic acid content showed a decreasing trend from 14 to 42 DAFS in 'Calcuttia' and 7 to 42 DAFS in 'Seedless'. At optimum maturity, 'Seedless' exhibited higher TPC, flavanol, proanthocyanidin, and phenolic acid contents in comparison to 'Calcuttia' cultivar.

Litchi fruit contains flavonoids, phenolic acids, and proanthocyanins as major phenolic constituents (WANG et al., 2011) that are present in abundance in pericarp. Various factors such as genotype and developmental stage, agronomic, post-harvest processing conditions, and environment can affect concentration and composition of these phenolics and activities of enzymes related to their metabolism (MiLIVoJEvic et al., 2012), and variations in TPC in litchi cultivars and species have been reported (Sun et al., 2009; Lin et al., 2015). The changes in PAL activity and TPC in LFP in this study showed the similar trend at different development stages as observed earlier in longan fruit (Yu et al., 2010). Both cultivars exhibited higher contents of TPC due to presence of higher amounts of flavonols and phenolic acids in the later stages of fruit development. The decrease in proanthocyanidins of LFP towards maturity might be either due to their reduced synthesis, conversion to other compounds, or decreased PAL activity and increased levels of flavonols. Decreased level of proanthocyanidins coincided with the increasing trend of anthocyanins in LFP near maturity as reported earlier by LAI and co-workers (2015).

\subsection{Activities of PAL, PPO, POD, and $C 4 \mathrm{H}$ of litchi fruit pericarp}

Polyphenol oxidase and PAL activities increased significantly in LFP from 14 to 21 DAFS in both cultivars at $5 \%$ significance level (Fig. 2). Polyphenol oxidase decreased gradually with the advancement in fruit development, remained almost constant for 21 days, subsequently followed by a small increment during the ripening period. Polyphenol oxidase activity was 1.2-2.1-fold higher in 'Calcuttia' than 'Seedless' at different development stages. Phenylalanine ammonia lyase activity decreased from 21 to 42 DAFS and then showed an increasing trend up to 56 DAFS. Significant differences in PAL activity in LFP were observed between 'Seedless' and 'Calcuttia' cultivars from 42 to 56 DAFS. Peroxidase activity showed an increasing trend in LFP of both cultivars from 28 DAFS up to maturity with significantly higher activity (approx. twofold) in 'Seedless' as compared to 'Calcuttia' from 42-56 DAFS (Fig. 2). Cinnamate-4-hydroxylase showed a significant increase in its activity in pericarp 

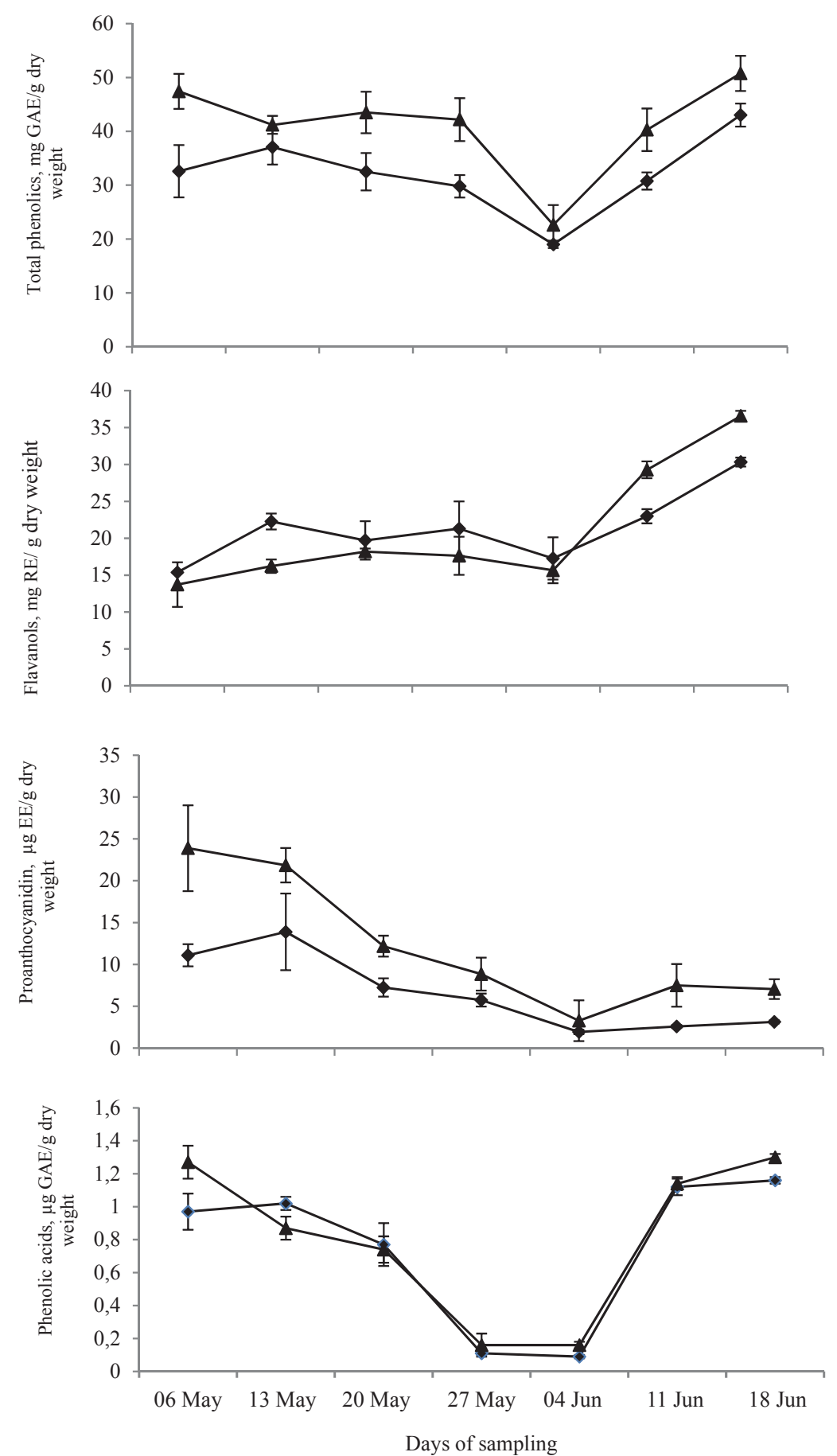

Fig. 1. Total phenolics (a), flavanols (b), proanthocyanidins (c), and phenolic acids (d) in pericarp tissue of litchi cultivars at different developmental stages. Values are mean $\pm \mathrm{SD}, \mathrm{n}=3$. Vertical bars depict the standard variation at $\mathrm{P}<0.05$. $\multimap$ : Calcuttia; ——: Seedless 
tissue of 'Calcuttia' from 14 to 21 DAFS followed by a decrease up to maturity. However, it showed a significant increase from 14 to 42 DAFS in 'Seedless', and then varied nonsignificantly up to maturity. 'Seedless' exhibited about 2-fold higher $\mathrm{C} 4 \mathrm{H}$ activity than 'Calcuttia' cultivar from 35-56 DAFS.
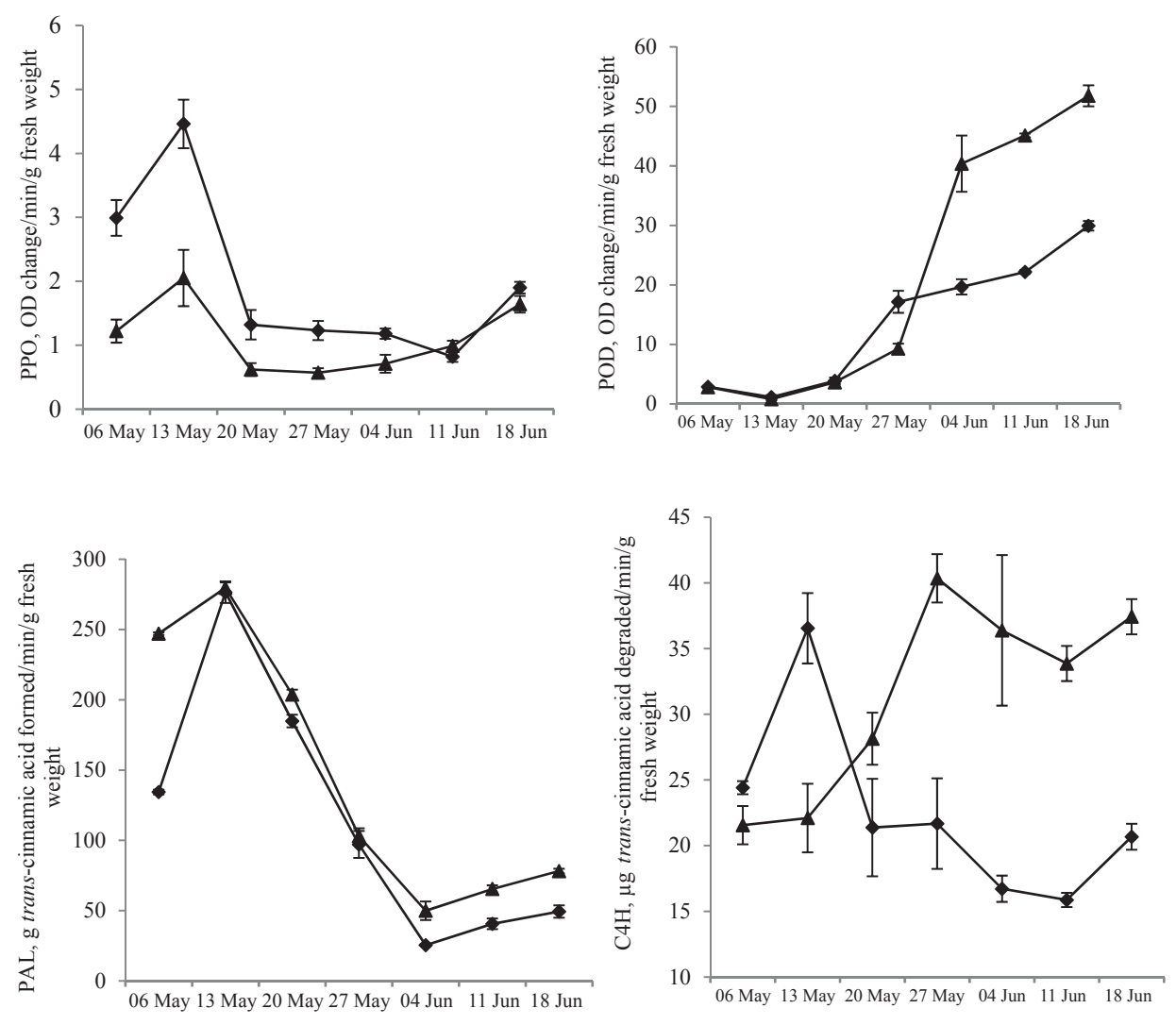

Days of sampling

Fig. 2. Polyphenol oxidase, peroxidase, phenylalanine ammonia lyase, and cinnamate-4-hydroxylase activities in pericarp tissue of litchi cultivar at different developmental stages. Values are mean $\pm \mathrm{SD}, \mathrm{n}=3$. Vertical bars depict the standard variation at $\mathrm{P}<0.05$. $\neg$ : Calcuttia; $\neg$ : Seedless

Changes in PPO and $\mathrm{C} 4 \mathrm{H}$ activities followed the similar trend as observed in TPC in pericarp during different fruit development stages. Mean POD activity at different stages was 19.7- and 6.9-fold higher than PPO in 'Seedless' and 'Calcuttia' cultivars, respectively. Similar changes in POD and PPO in litchi were reported earlier by ZAUBERMAN and coworkers (1991), ZHANG and co-workers (2005), and DuCAMP-CoLLIN and co-workers (2007). Polyphenol oxidase activity was significantly lower in pericarp of 'Seedless' as compared to 'Calcuttia' cultivar till 4 weeks after full bloom stage, and then non-significant variations were recorded up to maturity. The higher TPC with low PPO activity in pericarp during initial stages of fruit development in 'Seedless' as compared to 'Calcuttia' suggest that ripening 
occur at slow pace in these fruit. An initially higher PPO activity, followed by a gradual decline, and thereafter, increase in the activity during maturity in litchi (Sun et al., 2009) and longan (Yu et al., 2010) has been reported.

\subsection{Anthocyanins and anthocyanase enzyme in litchi fruit pericarp}

During the initial stages of fruit development, the anthocyanin content in pericarp was almost negligible and content recorded after the appearance of some yellowness and redness in pericarp with significant differences observed during fruit maturation (Fig. 3). Anthocyanin content increased with the fruit development up to 49 DAFS in 'Calcuttia' and 'Seedless' and then decreased up to 56 DAFS due to some degradation of anthocyanin to anthocyanidin after the stage of optimum maturity. Higher anthocyanin content was observed in 'Seedless' than 'Calcuttia' cultivar at different development stages of litchi fruit. Anthocyanase activity increased significantly from 21 to 35 DAFS and then decreased up to 49 DAFS in both cultivars (Fig. 3). Changes in anthocyanin content and activity of anthocyanase enzyme were negatively correlated $\{\mathrm{R}=-0.881$ ('Calcuttia') and -0.828 ('Seedless') at $\mathrm{P}<0.05\}$, and at maturity, 'Calcuttia' exhibited higher anthocyanase activity with lower anthocyanin content.
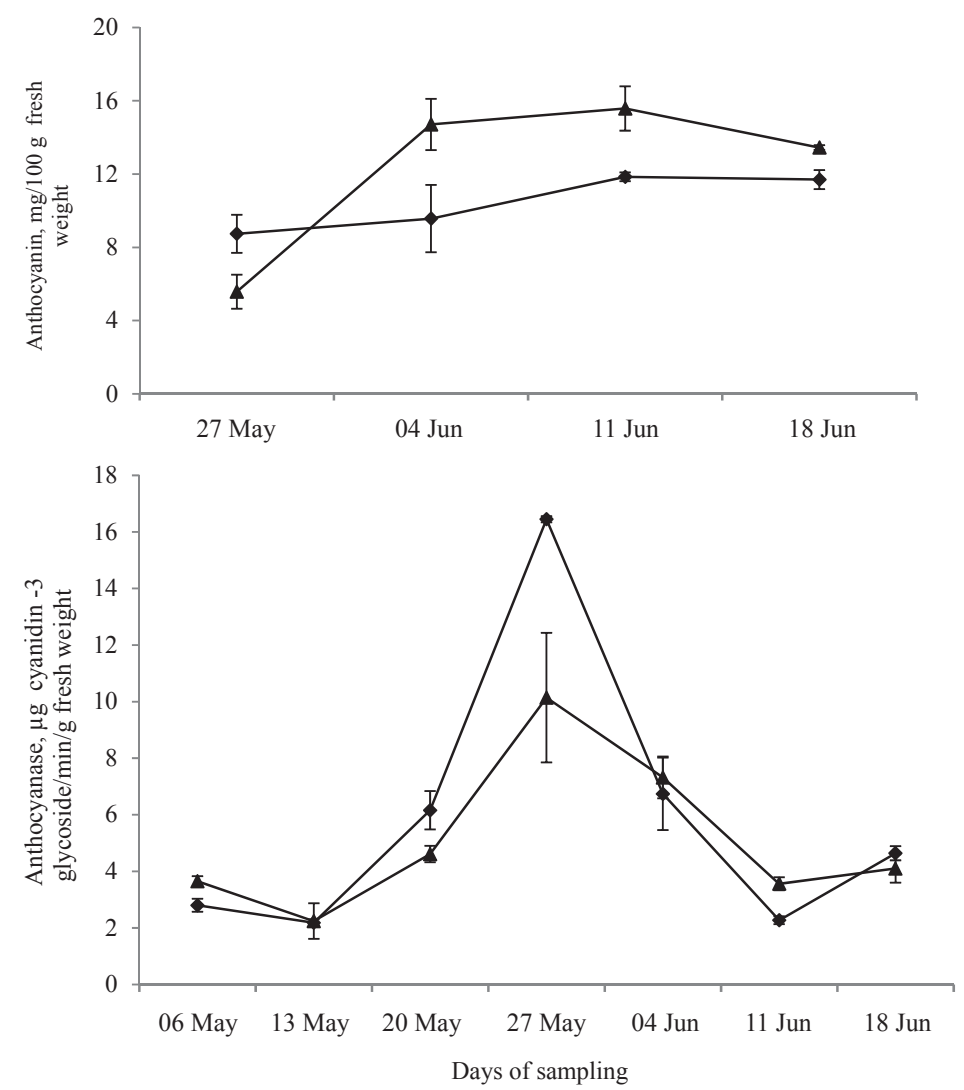

Fig. 3. Anthocyanin content and anthocyanase activity in pericarp tissue of litchi cultivars at different developmental stages. Values are mean $\pm \mathrm{SD}, \mathrm{n}=3$. Vertical bars depict the standard variation at $\mathrm{P}<0.05$. $\multimap$ Calcuttia; ——: Seedless 
Anthocyanase is an enzyme that catalyses the removal of sugar moiety from anthocyanin to synthesize anthocyanidins, which then act as substrate for PPO and POD in presence of phenolic compounds to form brown coloured product (JIANG et al., 2004). In the present study, lower anthocyanase activity during the initial stage of fruit development (14 to 21 DAFS) is attributed to low availability of the substrate due to presence of negligible amount of anthocyanin during this period. DuCAmp-Collin and co-workers (2007) reported that anthocyanase activity was in correspondence with anthocyanin content at the respective developmental stages with almost double in cultivar 'Kwai May' than 'Wai Chee'. The decrease in anthocyanin content from 49 to 56 DAFS might be due to some degradation of anthocyanin to anthocyanidin after the stage of optimum maturity.

\subsection{Antioxidant activity}

Antioxidant activity in LFP in ripened fruit revealed higher DPPH radical scavenging activity and FRAP value in 'Seedless' than 'Calcuttia' cultivar (Table 1). Antioxidant activity protects the biological molecules from oxidative stress generated by production of reactive oxygen species and reactive nitrogen species (Guo et al., 2003), and generally, not all fruit possess the same antioxidant composition and antioxidant activity. Higher antioxidant activity in case of 'Seedless' was attributed to the higher amount of phenolic constituents in its fruit as compared to 'Calcuttia' cultivar.

Table 1. 2,2-Diphenyl-1-picryl-hydrazyl radical scavenging activity and FRAP value in litchi fruit pericarp at maturity

\begin{tabular}{lcc}
\hline Parameters & \multicolumn{2}{c}{ Cultivars } \\
\cline { 2 - 3 } & 'Calcuttia' & 'Seedless' \\
\hline DPPH scavenging activity (\%) & $66.4 \pm 1.45$ & $83.6 \pm 1.10^{\mathrm{a}}$ \\
FRAP (mmol of $\mathrm{FeSO}_{4}$ formed/g fresh weight) & $8.80 \pm 0.02$ & $9.25 \pm 0.35^{\text {ns }}$ \\
\hline
\end{tabular}

Values are mean $\pm \mathrm{SD}, \mathrm{n}=3 ;{ }^{\mathrm{a}}$ : significant at $\mathrm{P}<0.05 ;{ }^{\mathrm{ns}}$ : non-significant

\section{Conclusions}

Significant variations in phenolic constituents, activities of enzymes of phenol metabolism, and antioxidant activity in the fruit pericarp were observed in 'Seedless' and 'Calcuttia' cultivars. Pericarp, a waste product of litchi fruit, is rich in phenolics with high antioxidant activity, and can be used as a source of natural antioxidants.

\section{References}

Balababa, S.I., ZaKe, A.Y. \& Elshamy, A.M. (1974): Total flavonol and rutin content of the different organs of Sophora japonica L. J. AOAC Int., 57, 752-755.

Benzie, F.F. \& Strain, J.J. (1999): Ferric reducing/antioxidant power assay: Direct measure of total antioxidant activity of biological fluids and modified version for simultaneous measurement of total antioxidant power and ascorbic acid concentration. Methods Enzymol., 299, 15-23. 
Ducamp-Collin, M.N., Lebrun, M., Ramarson, H. \& Self, G. (2007): Anthocyanins and anthocyanin-degrading enzymes in Kwai May and Wai Chee cultivars of litchis grown in Reunion Island and Spain. Fruits, 62, $353-359$.

Guo, C., YAnG, J., Wei, J., Li, Y., Xu, J. \& JiAnG, Y. (2003): Antioxidant activities of peel, pulp and seed fractions of common fruits as determined by FRAP assay. Nutr. Res., 23, 1791-1796.

JiAng, Y., Duan, X., Joyce, D., Zhang, Z. \& Li, J. (2004): Advances in understanding of enzymatic browning in harvested litchi fruit. Food Chem., 88, 443-446.

Lai, B., Hu, B., Qin, Y.H., Zhao, J.T., Wang, H.C. \& Hu, G.B. (2015): Transcriptomic analysis of Litchi chinensis pericarp during maturation with a focus on chlorophyll degradation and flavonoid biosynthesis. BMC Genomics, 16, 225-243.

Li, W., Liang, H., Zhang, M., Zhang, R., Deng, Y., Wei, Z., Zhang, Y. \& Tang, X. (2012): Phenolic profiles and antioxidant activity of litchi (Litchi chinensis Sonn.) fruit pericarp from different commercially available cultivars. Molecules, 17, 14954-14567.

Lin, Y.C., Chang, J.C., Cheng, S.Y., Wang, C.M., Jhan, Y.L., Lo, I.W., Hsu, Y.M., Liaw, C.C., Hwang, C.C. \& Chou, C.H. (2015): New bioactive chromanes from Litchi chinensis. J. Agr. Food Chem., 63, 2472-2478.

Lister, C.E., Lancaster, J.E. \& Walker, J.R.L. (1996): Phenylalanine ammonia-lyase (PAL) activity and its relationship to anthocyanin and flavonoid levels in New Zealand-grown apple cultivars. J. Am. Soc. Hortic. Sci., 121, 281-285.

Milivojevic, J., Slatnar, A., Mikulic-Petkovsek, M., Stamper, F., Nikolic, M. \& Veberic, R. (2012): The influence of early yield on the accumulation of major taste and health related compounds in black and red currant cultivars. J. Agr. Food Chem., 60, 2682-2691.

Ranganna, S. (1997): Handbook of analysis and quality control for fruits and vegetable products. Tata McGraw Hill Publ. Co., New Delhi, pp. 112-140.

Shannon, L.M., Kay, E. \& Lew, J.Y. (1966): Peroxidase isozymes from horse radish roots I. Isolation and physical properties. J. Biol. Chem., 241, 2166-2172.

Singh, K., Kumar, S., Rani, A., Gulati, A. \& Ahuja, P.S. (2009): Phenylalanine ammonia-lyase (PAL) and cinnamate 4-hydroxylase $(\mathrm{C} 4 \mathrm{H})$ and catechins (flavan-3-ols) accumulation in tea. Funct. Integr. Genomic., 9, $125-134$.

Sun, J., Xiang, X., Yu, C., Shi, J., Peng, H., Yang, B., Yang, S., Yang, E. \& Jiang, Y. (2009): Variations in contents of browning substrates and activities of some related enzymes during litchi fruit development. Sci. Hortic.Amsterdam, 120, 555-559.

Swain, T. \& Hillis, W.E. (1959): The phenolic constituents of Prunus domestice L. the quantitative analysis of phenolic constitution. J. Sci. Food Agr., 10, 63-68.

Upadhyaya, D.C. \& Upadhyaya, C.P. (2017): Bioactive compounds and medicinal properties of Litchi chinensis. -in: Kumar, M., Kumar, V., Prasad, R. \& Varma, A. (Eds) The lychee biotechnology. Springer, Singapore, pp 333-361.

WANG, L., Lou, G., MA, Z. \& LiU, X. (2011): Chemical constituents with antioxidant activities from litchi (Litchi chinensis Sonn.) seeds. Food Chem., 126, 1081-1087.

Yu, C., Sun, J., XIANG, X., YANG, B. \& JiAnG, Y. (2010): Variations in contents of (-) epicatechin and activities of phenylalanine ammonia lyase and polyphenol oxidase of longan fruit during development. Sci. Hortic.Amsterdam, 125, 230-232.

Zauberman, G., Ronen, R., Akerman, M., Weksler, A., Rot, I. \& Fuchs, Y. (1991): Postharvest retention of the red colour of litchi fruit pericarp. Sci. Hortic.-Amsterdam, 47, 89-97.

Zhang, D., Quantick, P.C. \& Grigor, J.M. (2000): Changes in phenolic compounds in litchi (Litchi chinensis Sonn.) fruit during postharvest storage. Postharvest Biol. Tec., 19, 165-172.

Zhang, Z., PAng, X., Xuewu, D., Ji, Z. \& JiAnG, Y. (2005): Role of peroxidase in anthocyanin degradation in litchi fruit pericarp. Food Chem., 90, 47-52. 